\title{
Finding creative processes in learning design patterns
}

\author{
Robyn Philip \\ Queensland University of Technology
}

\begin{abstract}
Bridging the gap between theory and practice in higher education continues to be problematic for educators. One potential means of addressing this problem and moving practice forward is to articulate and share learning designs created from the work of exemplary practitioners. This study offers a new representation of learning design which foregrounds creative processes. The learning design patterns are in text and visual format, and they reveal where creative processes reside in the learning process. The patterns are complemented by case study narratives, so there is an opportunity to bring significant insight to pedagogical practice. The designs were derived from an in-depth, qualitative study of exemplary practitioners who teach creatively and foster student creativity within either the creative industries or social sciences. Constructivist, informed grounded theory methods were used for the case study data collection and analysis that led to the construction of the patterns. The two case study examples chosen for discussion in this paper were distilled from blended learning units where online and face-to-face learning technologies were utilised. The learning designs discussed represent an original contribution to the field and have potential to be adapted to other disciplines, beyond those from which they originated.
\end{abstract}

Translating educational theory and research into practice can be problematic, so the search continues for credible ways to share effective and exemplary practice more broadly amongst higher education practitioners. There is a need for contextualised models and representations that are accessible, easy to use, and adaptable (Bennett et al., 2007; Bower, 2017; Goodyear \& Retalis, 2010). Representations and models that take the form of case studies and learning design patterns may prove useful as tools and resources to assist educators to conceptualise new and alternative approaches to learning, especially where the task is the complex one of designing for the development of learners' creative capacities. Students in all disciplines need creative capabilities: creativity is not an attribute confined only to, for example, the creative and performing arts. In addition, Bower (2017), Laurillard (2012), Conole et al., (2008), Goodyear and Retalis (2010), and Barab and Squire (2004) argue that the development of student learning experiences should be more design-based, that is, initiated and supported by a process of purposive design, which is creative and iterative.

Until recently, the discourse and emphasis of learning outcomes in higher education curricula has tended to favour students' analytical and critical capabilities. Creativity has received less attention in the discourse (Swirski, 2012), and become somewhat invisible (Jackson, Oliver, Shaw, \& Wisdom, 2006). Yet creativity requires both generative and analytical thinking skills (Fryer, 2012), and in Bloom's revised taxonomy of learning outcomes (Anderson \& Krathwohl, 2001), creativity is credited with being the most complex of all cognitive activities.

The role of creativity as a significant element of the learning process has been argued by key educationalists (e.g., Dewey, 1910; Freire, 2000; Jackson et al., 2006; McWilliam \& Dawson, 2008). Increasingly, international and Australian governments report and confirm the place of creativity in curricula at all educational levels (Australian Curriculum, Assessment and Reporting Authority, 2017; Australian Government, 2013; Bradley, Noonan, Nugent, \& Scales, 2008; European University Association, 2007; Gonski et al., 2011; Niu, 2006; Smith-Bingham, 2006). Further, in an uncertain and complex post-industrial world, constantly transformed by new digital technologies, it is important that educators nurture students' potential as creative problem solvers and engaged citizens who can reimagine and shape their futures. Educational institutions that do not prepare students for a challenging future run the risk of being bypassed as irrelevant, and even redundant (Arvanitakis \& Hornsby, 2016).

There is evidence, however, that higher education practitioners have difficulty successfully embedding this capability into curricula, that is, expressing, fostering, designing for and explicitly seeing and measuring 
creativity (Bridgstock, 2009; Fryer, 2006; McWilliam \& Dawson, 2008; McWilliam, Dawson, \& Tan, 2011; Oliver, 2011; Philip, 2015a). Not all practitioners are confident in their ability to design for and implement creative learning outcomes (Ball, 2010; Jackson, 2006; Philip, 2015a, 2015b; Walker \& Gleaves, 2008), even though the number of pedagogical guides to assist educators continues to grow (e.g., Ball, 2010; Nygaard, Courtney, \& Holtham, 2010; Seelig, 2012). In addition, the effective integration of digital learning technologies within an already complex design task can compound difficulties (Goodyear \& Retalis, 2010; Philip, 2015a).

This study offers a way forward in two ways: firstly, in the form of case-based narratives of creative learning and teaching. These provide contextualised, synthesised and rich descriptions of teachers' conceptions, values, approaches, and educational designs for fostering creativity. They uncover some of the tacit understandings that exemplary practitioners have around teaching creatively and teaching for creativity. While insights from the case studies are referred to in this paper, the principal focus is a description and discussion of the learning design patterns derived from the case studies. The learning designs, as a second strategy for supporting creative learning and teaching, are a means of capturing and representing excellent learning design, and explicitly revealing creative processes. For this, two new versions of learning design patterning have been created: (1) a modified text-based example that focuses on the creative processes inherent in a sequence of tasks; and (2) a new visual representation of learning design foregrounding creative processes using a flow chart format. When read together, the two forms of learning design, combined with the case narratives, provide a rich resource for practitioners. They can be utilised independently or, preferably, together, to uncover and reveal creative processes. Laurillard and McAndrew (2002) confirm the value and transferability of contextualised learning designs where outcomes, modelling of the learning experience, and context are well articulated (see also Bennett et al., 2007; Philip \& Cameron, 2008).

\section{The role of learning design in making creativity visible}

For the purposes of this discussion, creativity is defined as "the ability to produce work that is novel (i.e. original, unexpected), high in quality, and appropriate (i.e. useful, meets task constraints)" (Sternberg, Kaufman, \& Pretz, 2002, p. 1). Creativity is bound by culture and history (Amabile 1982; Csikszentmihalyi, 2007; Kaufman, Kornilov, Bristol, Tan, \& Grigorenko, 2010) and so will be perceived and valued differently in different disciplines and contexts. In western literature, intellectual interest in creativity has been documented back to ancient Greek times (Runco \& Albert, 2010), and has always been a concern of writers, artists and philosophers (Csikszentmihalyi, 2007).

So, beginning from the premise that learning is a creative activity, and the view that there is value in discovering where creativity resides in educational processes, leads to an interest in learning design. Learning design patterns have the potential to make learning visible, and therefore creative processes more visible. With deepened understanding of underlying educational and creative processes comes increased opportunity for innovation, and design for future-focused, forward-thinking pedagogy. Garzotto and Retalis (2009) argue that learning designs can foster creativity in two ways: through the design and development process; and the adaptation and reuse of designs in other contexts.

The field of learning design is relatively new to educational research within technology-enhanced learning (TEL) environments. According to Garzotto and Retalis (2009), early research into learning design emerged around 1999, and since then the field has advanced rapidly (e.g., Agostinho, Bennett, Lockyer, \& Harper, 2013; Dalziel et al., 2016; Goodyear \& Dimitriadis, 2013). The origins of educational design pattern language are typically attributed to the architect Christopher Alexander (Alexander et al., 1977). Alexander was interested in the communication of adaptable patterns as models that could be used for design and construction. The patterns were a method of documenting collective knowledge and creating real-world examples tested in practice: 
Each pattern describes a problem which occurs over and over again in our environment, and then describes the core of the solution to that problem in such a way that you can use this solution a million times over without ever doing it the same way twice. (Alexander et al., 1977, p. x)

In other words, the patterns are "a solution to a recurrent problem in a context" (Goodyear, 2005, p. 90) that can be continually repeated, and yet uniquely applied each time. Theoretically learning design patterns can be a means for bridging the gap between "philosophy, values, theory, empirical evidence and experience ... and the practical problems of design" (Goodyear, 2005, p. 90). As such, they are potentially of significant value to educators. Goodyear argues that Alexander's approach to design patterning provides guidance without constraining creativity. These patterns are "principled, structured, but flexible resources for vernacular design” (p. 90). Goodyear and Dimitriadis (2013) confirm the inherent creativity of designing for learning, which involves creative processes such as problem finding, problem reframing and problem solving. Further, in identifying the challenge of creative process, they argue that the process of designing for learning tends to be less about "optimising [towards] a single goal" and more about "reconciling competing forces" (p. 2), thereby highlighting the tensions inherent in creative activities.

There is a view that the term learning design is problematic because it infers that others' learning experiences can be designed, that is, made to eventuate, when in practice educators can really only design for learning. This is because learners will make of the context, tasks and learning environment what they choose (Goodyear \& Dimitriadis, 2013). I strongly agree with this view but, nonetheless, for convenience continue to use the term learning design with the understanding that we are talking about designing for learning. In addition, the term learning design as used in the literature can be employed as follows:

(1) to represent pedagogical designs as artefacts, that is, as the "documented outcome of the design process" (Agostinho, 2011, p. 962); (2) to refer to the process of designing learning experiences (Conole, 2009); or (3) as standardised Learning Designs (Koper \& Tattersall, 2005) [...] a standards-based approach to expressing learning designs via a formal language (Koper \& Tattersall, 2005) represented by the IMS specification (IMS Global, 2017). (Philip, 2015a, p. 44)

It is the first two conceptualisations of learning design that are relevant to this study.

There is no one method for representing learning designs either visually or in text. Early research in this domain tended to focus on the utilisation of content within learning activities (Conole \& Fill, 2005), and a number of representations have emerged over time, including flow diagrams, timelines, pie charts and course maps, depicting various levels of granularity (Dalziel et al., 2016). Design models that have influenced this study include representations used in the research of Australian Universities Teaching Committee (2003) learning design project, the work of Goodyear (2005), Kearney (2009), and the online role-play project, EnRoLE (EnRoLE, 2017; Wills, Leigh, \& Ip, 2011). Typically, these patterns include a description of the event or the expected learning experience, tasks designed by the educator, and activities undertaken by the learner, the resources and tools required, supports for the learning experience, timeframe, and an indication of interactions and relationships encountered between and amongst facilitators and learners.

A review of the literature on learning designs specifically concerned with patterns for creative tasks relevant to this study indicates that research in the domain is nascent, and that further in-depth investigation would be beneficial. Leaving aside any "how to be creative" guides which make claims to pattern language, a variety of models have been proposed for the purpose of promoting creativity or inquiry-based learning. Examples include the creative education patterns of Harashima, Kubota, and Iba (2014), who use a combined illustration/text-based pattern format and address seven descriptors in their sequences, namely pattern name, introductory sentence, illustration, context, problem, solution and consequence. Kimura, Shimizu, Ogo, Ando, and Iba (2016) and Kohls (2015) have chosen text-based models to exemplify pattern approaches for creative education programs and teaching students' creative thinking skills. Their models are shaped in the main around the descriptors context, problem, solution and consequence. Nagai, Isaku, Akado, and Iba's (2016) "generator patterns" employ flow chart and text-based patterns to document the role of "generator" in collaborative inquiry activities: a generator being a person who leads and builds creative teams. In their paper, 
Nagai et al. (2016) are concerned with one step in the creative and/or design process, namely idea generation. As a further example, and a critique of the efficacy of learning design patterns relating to inquiry-based learning, Dobozy and Campbell (2016) examined the relationship between two models for learning design: the learning design framework (LD-F) and the technology, pedagogy and content knowledge (TPACK) model. To illustrate synergies between the two approaches, Dobozy and Campbell created text-based models and visual flow diagrams. Their aim was to demonstrate how these patterns could be used as pedagogical tools in the transformation of a traditional lecture-style lesson into a creative, inquiry-based activity.

These models all represent useful lesson plans, with researchers such as Dobozy and Campbell (2016) contributing relevant discussion to the debate on learning design issues. However, the method of identifying and representing creative processes and opportunities, contextualised in a practice-based model, as demonstrated in this paper, was not found in any of the examples reviewed. In addition, review of the literature and the patterns found reinforces the view that identification of the design focus and the underpinning educational philosophy of the teacher and/or designer account for distinct differences in the construction of patterns. Differences in philosophy, emphasis, and intention lead to variation in the selection of methods for representing all of the contributing elements. Choices must inevitably be made about what to include or exclude in a pattern; and selecting a suitable communication style to articulate learning and teaching processes (and in this research, to foreground creative processes) remains problematic.

\section{Methodology}

The learning designs discussed in this research were derived from an exploratory study of creativity in learning and teaching in higher education. The aim of the study was to explore the views, motivations and educational approaches of exemplary higher education practitioners who teach creatively and design for student creativity. The research question that drove the study was: What lessons can be learnt about fostering and designing for creativity from educators in higher education, in particular, from exemplary practitioners? The impact of context was one of a number of considerations of the research, and this included the role of the TEL environments in which creativity was observed and explored. Following Goodyear and Retalis (2010), technology-enhanced learning is used broadly as an umbrella term to refer to networked learning, online learning and all forms of e-learning, including blended learning.

\section{Design of the research}

Case study data was collected and analysed using informed grounded theory methods (Thornberg, 2012). Grounded theory is a methodological approach to the collection and analysis of qualitative data developed by Glaser and Strauss (1967), whereby theory is inductively built from the data. Informed grounded theory is a constructivist version of grounded theory that allows for early integration of the literature review in the research design (Thornberg, 2012). A social constructivist epistemology (Phillips, 1995) underpinned the investigation and, therefore, the unique perspective that the researcher and participants brought to the learning, teaching, and research was respected and acknowledged at all stages of the research process. Ethics approval was sought from the University Ethics Committee and granted.

\section{Criteria for the choice of case studies}

Five exemplary academics known to teach creatively, and for creativity, were invited to participate in the research. The academics were unit coordinators recognised by their peers to be excellent, exemplary teachers. They were teachers who demonstrated a sound knowledge of their subject area, implemented innovative learning and teaching approaches, engaged and inspired students, encouraged high levels of student achievement, communicated well with students, and were committed to personal and professional development. The purposive sample was designed to maximise the possibilities for cross-case analysis and to provide variation in delivery mode (face-to-face, blended and fully online). Evidence of exemplary creative pedagogical practice was determined not only via recommendations from trusted peers, but also through examination of the stated unit learning outcomes that either explicitly or implicitly encouraged student 
creativity. In addition, the curriculum of exemplary teachers needed to provide evidence of aligned pedagogical design and exemplary use of learning technologies. Further, access to the unit for the purposes of the study needed to be relatively straightforward and cause little if any disturbance to routine teaching and learning activities. Each case provided a snapshot of pedagogical practice within a twelve- or thirteen-week Australian university semester (in 2012 or 2013).

\section{Data gathering}

The research design was systematically planned and framed from the outset and, in line with grounded theory practice (Charmaz, 2011; Strauss \& Corbin, 1990), data gathering was modified as the research evolved, and as ongoing reflection and theoretical sampling demanded. The recursive process of data gathering was repeated until no new data emerged, and within scope of the project. Qualitative data was gathered from five case studies of exemplary practitioners: four from the creative industries (creative writing, digital imaging, web interface design and architecture), and one from the social sciences (sociology). The data included semistructured interviews with teaching staff (unit coordinators) $(n=5)$, and a selection of invited tutors from each unit $(n=15)$, and focus groups and interviews with students $(n=31)$ recruited through email and personal invitation. Classroom observation, field notes and unit-related documentation completed the data triangulation process. Pseudonyms were created for all case study participants, including unit coordinators, tutors and students.

\section{Data analysis}

Constructivist informed grounded theory methods (Charmaz, 2011; Thornberg, 2012) were employed to collect and analyse the qualitative data. The learning designs as artefacts were synthesised as part of the larger process of grounded theory analysis of all the aggregated data. This was a seven-stage process (see Figure 1). Stage 1 was the preliminary analysis, when case material was recorded and reviewed; concepts maps, conceptual memos, and journal entries were created; and temporary matrices and tables comparing preliminary findings from each case were constructed. During stage 2, following a preliminary analysis of the audio interviews and focus groups, basic narratives of each case were created and early theoretical insights recorded. During stages 3, NVivo software was employed to support the process of initial data coding, and in stage 4 focused coding of the resulting codes was undertaken to create refined categories of concepts from the data. Stage 5 was another period of ensuring each case was examined holistically in its entirety, and draft learning design patterns in text and graphic format were created. During stage 6, relationships between the conceptual categories were verified and challenged through episodes of constant comparison of the data. The learning design patterns were further refined and verified with reference to the transcripts of interviews, field notes, the unit outlines, and classroom observation (on and offline), which included dialogue with the unit coordinators to confirm details of their designs. The final stage of theoretical sufficiency was reached when theory emerged in its final form from the data (see Figure 1).

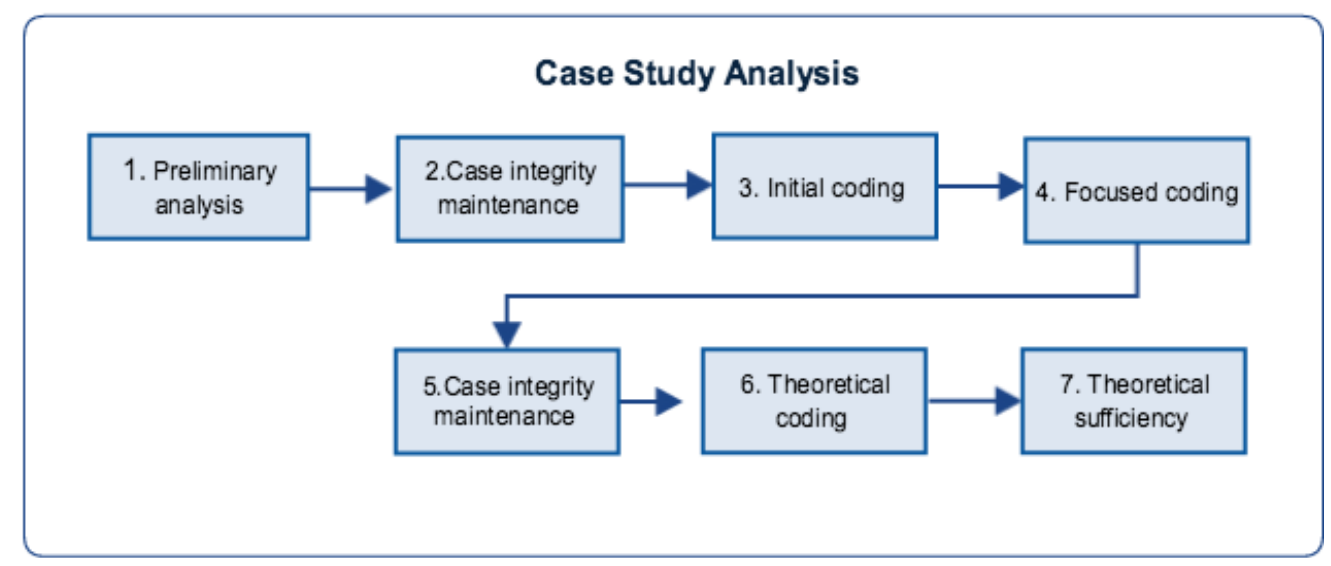

Figure 1. Grounded theory steps for the case study analysis. Source: Philip (2015a, p. 78) 


\section{Findings}

\section{Creation of the learning designs}

Two models emerged from the study as suitable means for expressing creativity within learning design patterns: firstly, a text-based model, adapting features of the EnRoLE online role-play project models (EnRoLE, 2017) (see Figure 2), and an original representation in visual flow chart form (see Figures 3).

Generation of the learning designs required involvement of the teacher as designer, and the researcher. As Conole et al. (2008, p. 182) have observed, producing learning designs is a "messy, creative and interactive process ... even when working in teams there is a large element of individuality in the design process". The learning designs were drafted firstly as rough hand-drawn flow charts. A detailed textual pattern was then constructed for each case. The draft textual patterns that emerged were found to have similarity to EnRoLE models (EnRoLE, 2017), and their final form represents a synthesis of EnRoLE models, with a new form, iteratively derived via grounded theory processes. The chosen representation included the sequence of tasks and expected creative learning outcomes and opportunities for creativity, with the teaching perspective uppermost (see Figure 2). A description of the task, keywords, the target audience, group size and setting, time frame for the whole series of tasks, expected creative learning opportunities, resources required to support the creative components of the task, supports for students' learning, and a short summary of the learning tasks were included.

The headings used in this model varied slightly from the original EnRoLE model (EnRoLE, 2017) (which were abstract, description, audience/group size, learning opportunities, time and setting, resources, learning activities, reusability), as the aim was to bring the creative processes and opportunities into focus. This meant that the designs were not created to articulate every aspect of the learning event, but to represent the key creative components, with sufficient detail to make the design replicable. This is not a limitation, but a focus. In the generation of any learning design the philosophical principle of Ockham's razor needs to be invoked, where a choice is made between sufficient detail to articulate the learning design, and representation in its simplest form. For example, in case 2 (see Figure 2), a web interface design activity, the resources for supporting creativity included many digital tools (blogs, interface design websites, the learning management system, software applications for visual design production), which were listed, but analogue tools such as pen and paper recommended in the unit outline were not. The latter were assumed resources as the pattern cannot contain every possible tool required.

The EnRoLE (2017) model was suitably adaptable for highlighting the creative components of each design. It provided a framework within which fluidity and choice could be indicated. This was important in the context of searching for creativity, as paradoxically, for creativity to emerge it is necessary that there are boundaries to constrain work, but maximum opportunity within boundaries for play and generation of an original product (Philip, 2015a). Also, adaptation is a form of creativity. Each of the text-based models was two pages in length, so only a compressed example from case 2 has been included here (see Figure 2).

\section{Title: Develop a Concept. A Brief for a Web Interface Design Project}

Description: The student's brief is to develop a concept for a web interface design from the first stage of problem finding, to the proof of concept (POC) stage, as a 'first draft' only. (The finalised POC is presented in a subsequent assignment.) Students are expected to create three posters representing their creative work over that period. The first poster represents students' independent research and a critical analysis of emerging user interface trends in the industry. The poster is presented to the class for discussion and sharing in week 3 . The other two posters address the next steps in response to the design brief. The second poster includes research into possible competing designs already in the marketplace, problem definition and framing of the student's proposed concept, narrowing the focus and scope. The last poster represents proof of concept, and the feasibility of the project. In the third step students describe and provide a rationale for the project and use sample screen designs and layouts for demonstration. Each time when the posters are presented, students in the class act as a diverse peer review audience, providing constructive feedback, and replicating industry practice. 


\begin{abstract}
Keywords: Design process, web interface design and interaction, peer review
Target audience, group size and setting: Undergraduate web interface design 200-level, in tutorial group, 20-25 in a face-to-face (on-campus) setting. (Adaptable to the fully online setting.)

Timeframe: 6 weeks of a 13-week semester: Preparation begins in week 1 . The 1st poster is due in week 3 and two more in week 6.
\end{abstract}

\title{
Creative learning opportunities
}

- $\quad$ Produce design solutions to complex design briefs following an iterative design process.

- $\quad$ Respond to a design brief from problem finding to proof of concept.

- $\quad$ Apply interface design and technical skills in a range of contexts.

- $\quad$ Continual iterative research into the state of the art (web interface design).

- Test audience responses to creative work (formative and summative).

- Develop ability to articulate (explain, justify and communicate) creative decisions graphically, verbally and technically.

- Reflect on one’s own and others' creative style, aesthetics, design processes and techniques via the peer review process.

\section{Resources (artefacts to support creativity)}

- $\quad$ Examples of exemplary interface design from a variety of developers and genres.

- $\quad$ Recommended articles and websites on design process and technical aspects, lecture notes and tutorials on the web and via Lynda.com.

- $\quad$ Resources researched and found by students for inspiration and motivation-sourced from the world around and the Internet.

- Learning management system as a central point for communication and content repository.

- Schedule for production of artefacts, linked to assessment.

- $\quad$ Guidelines for critiquing others' work during the poster presentation process.

- A tutor's blog with screencasts of tutorial work and supporting comments is a useful addition to the process.

\section{Supports to facilitate the design process}

- A supportive creative environment that motivates students to go beyond what already exists, and design something original and appropriate.

- A supportive lecture and tutorial environment that promotes students' confident sharing of designs with peers and tutor.

- $\quad$ A readiness to listen and learn from others during the peer review process, and challenge assumptions.

- Students can be encouraged to set up personal blogs to demonstrate concept development and comment on others' work.

\section{Sequence of activities}

1. Student provided with design brief.

a) Student imagines or finds a problem to solve which addresses a specific human experience (e.g. a mobile phone or tablet application that improves the experience of having a meal).

b) Student creates a poster based on their critical research addressing the problem.

c) Posters are exhibited in class as a gallery, and students critique each other's work, discussing the designs and adding Post-it (sticky) notes with constructive feedback to a selection of posters. The results are discussed in groups and as a class. Poster is submitted for summative assessment.

2. Design and frame the problem:

a) Building on step 1, student focuses on defining and framing the problem.

Student goes through iterative stages of generating many solutions to the problem (ideation), then narrowing the choice down, selecting an option and comparing it with other competing options.

a) Student creates poster demonstrating concepts and research.

b) Posters are exhibited in class for peer review following description in step 1c.

3. Proof of concept:

b) Student develops a solution to the brief, and creates a project synopsis, target user profiles and use case scenarios, using mockups, wireframes and other screen layouts and diagrams to illustrate the concept.

a) Student creates a poster to demonstrate solution.

b) Posters are exhibited in class for peer review following description in step 1c.

Figure 2. Text-based learning design pattern from a web interface design unit (case 2). Source: Philip (2015a, pp. 343-345) 
Figure 3 is the visual representation of the pattern described in Figure 2 (see also Figures 4 and 5 for greater detail). The pattern is for a six-week web interface design task. For the task students are asked to develop a prototype for a web application for a digital device such as a smartphone or tablet, and demonstrate proof of concept: that is, create a feasible model. The task involved typical design stages and processes, namely (1) find a problem to solve; (2) empathise with people who experience the problem and determine their needs and issues; (3) define the problem in a clear statement; (4) generate many ideas and alternatives (ideate), then choose one solution to pursue; and finally (5) make a model of a proposed solution (a prototype) to show proof of concept. Students were not required to complete the design cycle and go to the next stage of testing their model, or iteratively repeating the process until a suitable and valuable solution was achieved. The model just outlined is a typical design process model, such as that used by the Hasso Platner Institute of Design at Stanford (2010).

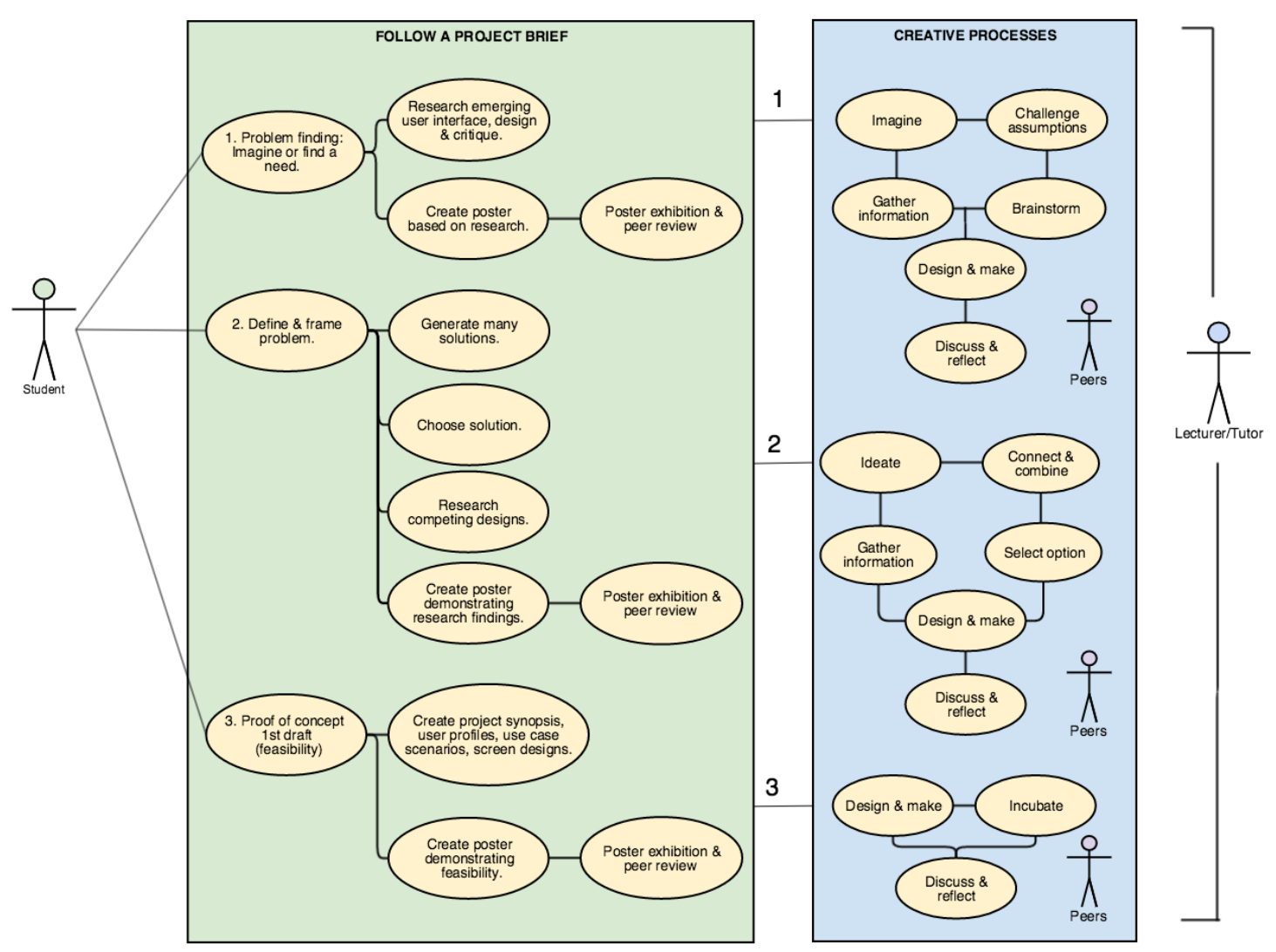

Figure 3. Learning design pattern foregrounding creative processes. Source: Philip (2015a, p. 165)

The steps of the overall task appear in the left-hand column of Figure 3, and the likely creative activities students would undertake in the right-hand column. The student is clearly located to the left of the model, indicating their engagement with all tasks; and the facilitator (lecturer and/or tutor) positioned on the right, as a supporter of process throughout. While the student is central to the creative learning process, work can be individual and/or collaborative or cooperative. Opportunities for group work are depicted by the figures labeled "peers" in the right-hand column. In this example, cooperative opportunities occurred when students exhibited their posters as a class "gallery", and then analysed and critiqued each other's research at the problem finding stage. This was a peer review exercise where feedback was given and received. Two other peer review opportunities were designed into the overall task when students exhibited two more posters in the gallery as representations of their work: firstly to demonstrate how they framed and defined the problem they had chosen to solve, articulating how it differed from other possible solutions (stages 2, 3 and 4 of the design cycle); and then lastly as proof of concept (stage 5). 
As a research and creative learning opportunity, the process of generating the learning designs in visual format was a valuable means of finding creative processes that could be less visible in the text-based alternative. While the teaching perspective was principally represented in the text version, the sparser visual form could be read as a more student-centred version with the student at the heart of the design. Both designs also created a frame of reference where responsibility for initiating process and creating a product resided principally with the learner (as recommended by Goodyear and Dimitriadis, 2013). The visual figures also give an idea of the flow of tasks and activities, individual interaction points, episodes of collaborative or cooperative peer interaction, and the facilitating role of the teacher throughout. This emphasises the sociocultural nature of creativity. As Csikszentmihalyi (2007) argues, creativity occurs in context, in a time and a place, in a domain and a culture. It is not just an individual phenomenon. (See Figures 4 and 5, which magnify Figure 2.)

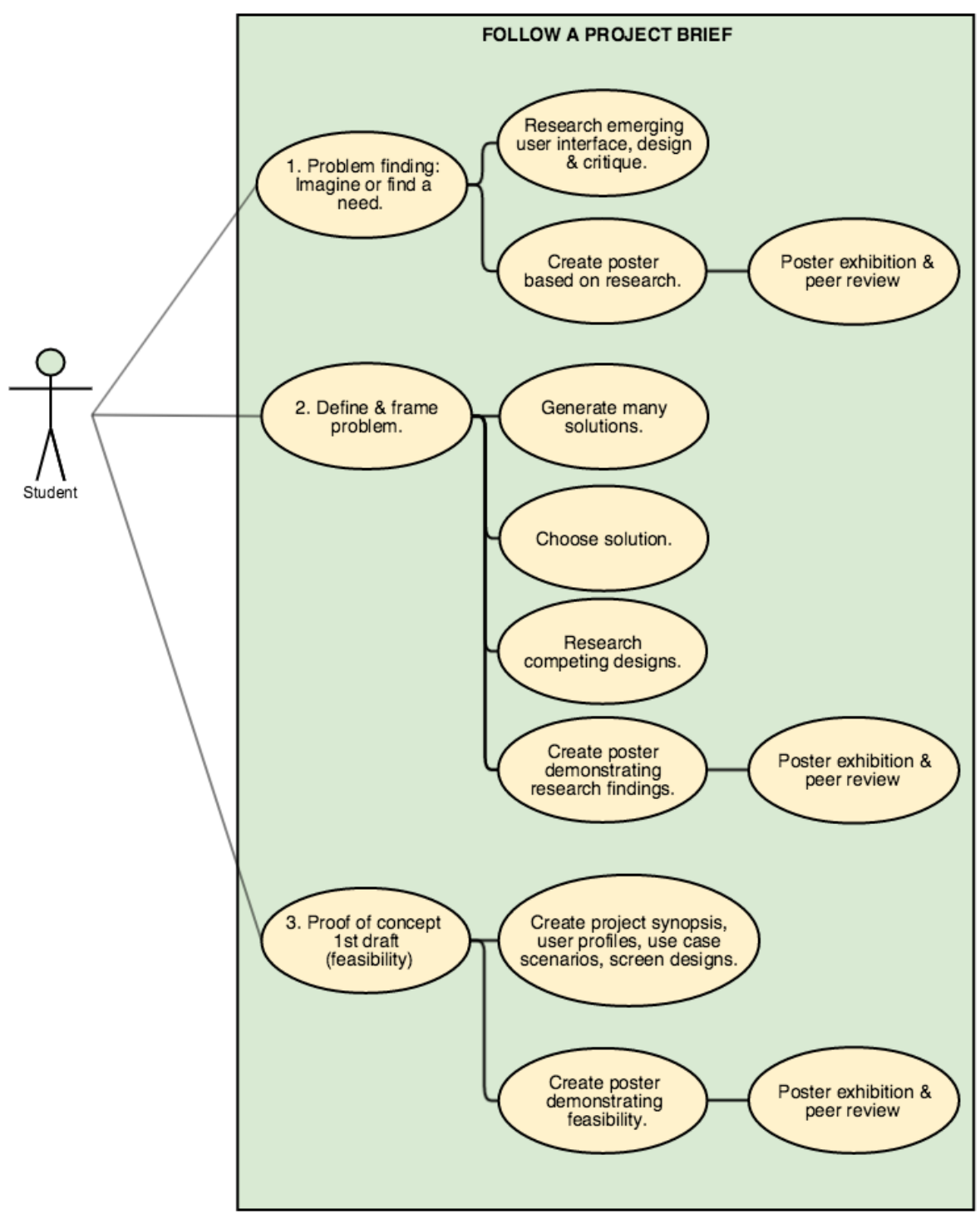

Figure 4. Steps of the project brief for a proof of concept task. Note: This is a magnified view of the left-hand column of Figure 3. 


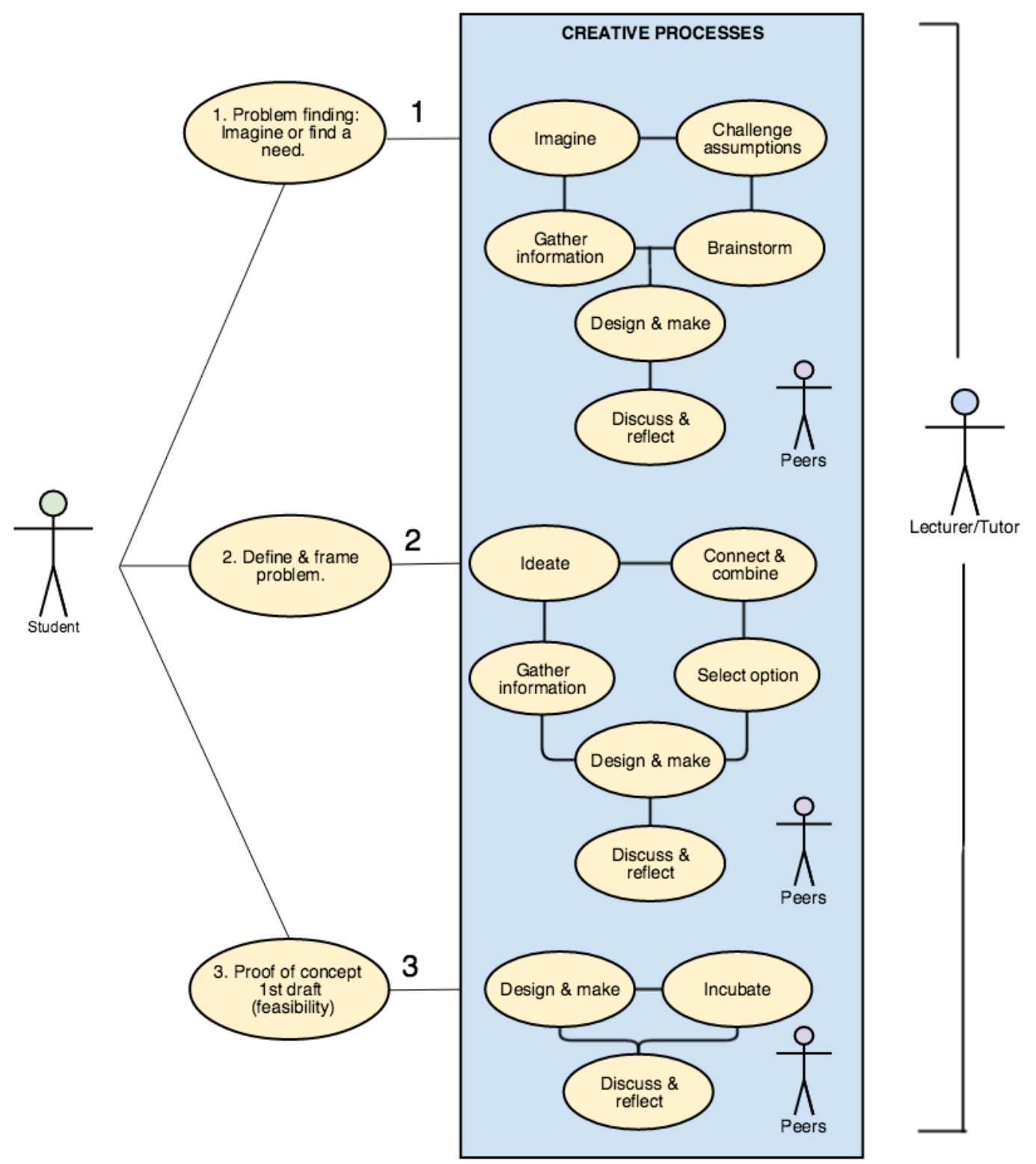

Figure 5. The likely creative processes accompanying a sequence of activities. Note: This is a magnified view of the right-hand column of Figure 3.

Finally, Figure 6 provides two examples from the case study narratives constructed from case 2. The excerpts provide a glimpse of the unit coordinator's values and pedagogical approach, the role and impact of digital and analogue technologies in the learning context, and the complexity of learning to "be creative". Where detail such as this is available, in addition to the learning design patterns, the combined documents become valuable heuristics, providing a more holistic picture of creativity in context and in practice. 
Kasumi's view on the role of ICTs in this context is that "the technology part is procedural, the building of ideas is not". The point is that there are procedural steps to using the technology. These steps can be learnt and followed in sequence, but learning how to be creative (in her words, to be energised, explore, see the world in a different way, connect and construct concepts) is non-linear. So from this point of view technology should be easier for students to learn than "being creative"; but Kasumi says that that is not how students see it.

While clearly revelling in new technologies, Kasumi still stresses the usefulness of non-digital tools, pen and paper, for sketching, storyboarding, researching concepts and prototyping. These analogue technologies are listed in the unit overview as requirements. The blogs, the pen and paper sketching, the development of wireframes and mockups are all means of rapid prototyping, getting ideas out there, making space for testing, communicating and receiving feedback from peers and others in the field. "Design is research," Kasumi says. It is active and purposeful.

Figure 6. Examples from the case 2 narrative. Note: Kasumi was the unit coordinator. ICTs = information and communication technologies. Source: Philip (2015a, p. 161-3)

\section{Locating hidden and implicit creativity}

While creative processes were readily apparent in the web interface design unit (case 2), it was useful to compare a unit from the creative industries with a more traditional social sciences unit, where creativity might be expected to be less visible or explicit. Figure 7 demonstrates the creative processes discovered in a unit on society and culture (case 3).

The learning design described in Figure 7 represents one week of tasks and activities in a blended learning unit on contemporary society and culture. As a first-year unit, the goal was to introduce students to sociological theory and university-level thinking. To meet the constraints of large class sizes, a blended learning approach was adopted incorporating two hours of face-to-face class time (one lecture, one tutorial) supplemented by online resources and tasks. The unit could also be taken as a fully online unit. Students needed to be carefully scaffolded through this introductory unit, especially given the limited face-to-face interaction with teachers and peers, and the ethnically diverse cohort that included many first-in-family students (first in their immediate family to go to university). A clear purpose of the unit was to challenge students’ thinking about society, particularly regarding stereotypes around ethnicity, class, gender and age.

Given this context and constraints on resources, the teaching approach demonstrated was a particularly creative one. Through interviews, in-class and online observation, and iterative analysis of the data, it was possible to locate and document the creativity in learning and teaching processes. It was embedded in the teaching during lectures and tutorials, in the resources provided to students for self-study, and the encouragement for students to actively engage in their learning. The onus was on students to be creative thinkers, to conduct their own observational research on a daily basis, and to be creative in devising their own examples as preparation for assessment tasks. The exemplary teacher, unit coordinator Alex, created amusing videos to engage and challenge students in the online space. The use of humour and play are known techniques for encouraging creativity (London Screenwriters, 2014). The unit coordinator played a key role in motivating students towards creative thinking by modelling creative practice during lectures, challenging assumptions at all opportunities, and ensuring a vibrant teaching presence in the online environment. During classes students were encouraged to participate in collaborative activities that often embodied creative forms such as music and theatre.

Unlike case 2, students in this unit were not overtly called to produce a creative product. However, they were implicitly and frequently encouraged to be creative learners. This was clear from the unit coordinator's personal philosophy of learning, expressed during interview and in practice. The creation of learning design patterns was an important step in recognising what might otherwise have been invisible creativity in this context. 
As explained, Figure 7 illustrates the learning design for a week of tasks. The left-hand column outlines steps such as read, respond, reply, and attend lectures and tutorials. On the surface, these would seem to promote passive student responses. However, closer inspection revealed creative learning opportunities for students. The right-hand column documents some of these moments. They include personal creative responses to motivation provided by the teacher; students finding their own unique problems to examine and question; connecting and combining ideas, prompted by paying attention to social interactions in one's own local environment, and synthesising those constructs with contemporary and historical sociological theories. Through practical application, complex theories were creatively made accessible. The teacher integrated known creative processes such as play, ideation and storytelling. Students were encouraged to express themselves and their creative choices through multiple media (e.g., within a closed group Facebook community), where peers and teachers responded and evaluated ideas. In addition, time was factored in for incubation of ideas (an important component of creativity), and online resources strategically deployed before face-to-face classes to stimulate creative student engagement. Alex expended much energy motivating students through his creative efforts, which encouraged active and memorable learning. Consequently, the learning design from case 3 demonstrates that seemingly passive activities can be reframed as creative learning opportunities (see Figure 7).

\section{CASE 3: SOCIETY \& CULTURE}

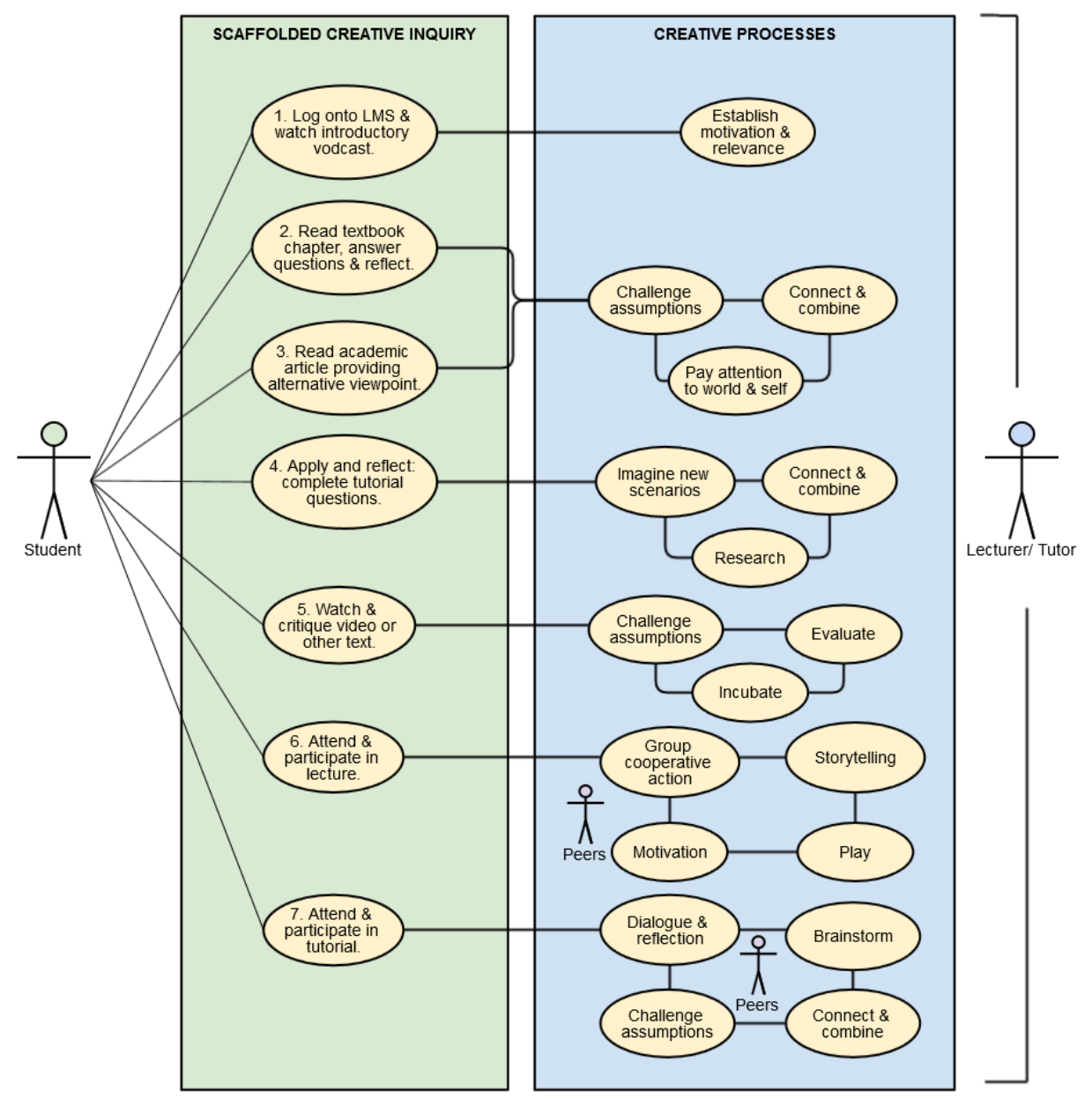

Figure 7: Creative processes made visible in a sociology unit. Source: Philip (2015a, p. 174) 


\section{Discussion}

The learning designs described here provide a lens through which creativity could be observed in practice. They proved suitable as a means of capturing the essence of the pedagogical approach, creative processes and the sequence of activities for a selected creative task. They helped identify where individual work predominated, and cooperative or collaborative peer interactions occurred. As expected, the iterative creative processes were abundant in the overtly creative units, such as case 2. But the exercise of creating learning designs helped realise hidden expressions of creativity in less expected contexts, such as case 3 , where the primary purpose of the unit was not overt creative expression or the design of a creative product. These cases demonstrate that learning and teaching are inherently creative activities as argued by Freire (2000), Dewey (1910), and Jackson et al. (2006).

In terms of reusability, the learning design models presented represent creativity at a level of granularity that supports unique and differential interpretation. They are customisable, and ready to be shared with educators from the same or other disciplines and modified as required. Although the basic steps for each design have been outlined, changes to the learning environment, the student cohort, the teachers, the tutors, or the technologies, will impact expression of the designs. There has been no attempt to cover all possible steps in the process - only a broad outline, sufficient for adaptation and reuse.

The focus of the learning designs was to find and foreground creative process: to reframe what we see in learning and teaching from a creative perspective. As a result of this the designs have helped shift the perspective from what the teacher designs (tasks) to what the student does (activities), while still presenting both perspectives. Figure 3 in particular offers the reader a sense of the flow of tasks and activities - that is, from the generation of ideas (which entails divergent thinking), through iterative episodes of analysis and decision making (which require convergent thinking). This study confirmed that both types of thinking divergent and convergent - are required for creativity to manifest. This is a position also held by theorists such as Jackson and Shaw (2006) and Runco (2011). The two learning design patterns (see Figures 2 and 3) are different but complementary, and combined with the case narratives provide much needed contextualised exemplars that potentially bridge the theory/practice divide.

Analysis of the learning design patterns and the case studies demonstrated that creativity can be designed for and fostered in higher education. But design for learning experiences is not sufficient to ensure effective implementation, and this study demonstrated that committed mentors are essential to the process. Mentors (unit coordinators and tutors) motivated students towards creative outcomes, modelled creative practice, established safe creative spaces for experimentation, and fostered a sense of community in which creativity could be realised. Context and discipline were seen to influence expressions of creativity, including whether or not creativity was implicitly or explicitly demonstrated in educational practice and design. In addition, the impact of the TEL environment in which the designs were implemented was not seen as an overwhelming barrier to fostering student creativity. It was treated as "one of many layers of complexity to be managed and shaped for creative and pedagogical ends” (Philip, 2015a, p. 240).

\section{Conclusion}

In answer to the research question regarding what can be learned about creativity from exemplary practitioners, the generation of learning design patterns underscored three important points, namely:

that learning and teaching are creative processes; that creativity is often hidden in the processes of learning and teaching; and that the generation of a learning design is a creative act in and of itself, as is the adaptation and implementation of a learning design. A learning design, therefore, either as process or as artefact, embodies the creator's philosophical approach to learning and teaching, and their creative values. (Philip, 2015a, p. 242) 
This research may be seen to be limited in that the models described and discussed focus on creative processes and outcomes but, as explained, this was the specific purpose of the research. Other research into learning design may focus on attributes that meet different research goals. Further, although these models represent actual educational practice, successfully implemented and tested many times with students in "live" classes, the patterns themselves (Figures 2 to 7), have not been tested with practitioners from other courses or disciplines. The learning designs are therefore potentially adaptable to other contexts, as much as any learning design can be. In addition, regarding limitations, as expected with qualitative research the findings are generalisable to theory, not to populations.

The generation of learning design patterns, and the documentation of contextual information in the form of case studies, is an important step in the process of building a rich picture of exemplary practitioner approaches to teaching creatively and fostering student creativity. The focus of this research has been to shed light on the elusive phenomenon of creativity, and to make it more visible. This discussion contributes to the much needed discourse on creativity in practice, and the search for effective methods of articulating teachers' expressions and pedagogical designs for creative learning and teaching. Future research could focus on testing the adaptability and reusability of the learning design patterns outlined to evaluate their efficacy and usability.

\section{Acknowledgements}

This research was conducted as part of a doctoral study conducted at Queensland University of Technology (QUT), under the supervision of Professor Ruth Bridgstock (Faculty of Creative Industries) and Dr Shaun Nykvist (Faculty of Education). I gratefully acknowledge their support and guidance during that time. I would also like to acknowledge the exemplary teachers who participated in this research, who generously shared their time and expertise.

\section{References}

Agostinho, S. (2011). The use of a visual learning design representation to support the design process of teaching in higher education. Australasian Journal of Educational Technology, 27(6), 961-978. https://doi.org/10.14742/ajet.923

Agostinho, S., Bennett, S., Lockyer, L., \& Harper, B. (2013). The future of learning design. London: Routledge. https://doi.org/10.1080/17439884.2011.553619

Alexander, C., Ishikawa, S., Silverstein, M., Jacobson, M., Fiksdahl-King, I., \& Angel, S. (1977). A pattern language: Towns, buildings, construction. New York, NY: Oxford University Press.

Amabile, T. (1982). Social psychology of creativity: A consensual assessment technique. Journal of Personality and Social Psychology, 43(5), 997-1013. https://doi.org/10.1037/0022-3514.43.5.997

Anderson, L. W., \& Krathwohl, D. R. (Eds.). (2001). A taxonomy for learning, teaching, and assessing: A revision of Bloom's taxonomy of educational objectives. New York, NY: Longman.

Arvanitakis, J., \& Hornsby, D. (Eds.). (2016). Are universities redundant? In J. Arvanitakis \& D. Hornsby (Eds.), Universities, the citizen scholar and the future of higher education (pp. 7-20). New York, NY: Palgrave Macmillan. https://doi.org/10.1057/9781137538697

Australian Curriculum, Assessment and Reporting Authority. (2017). Critical and creative thinking. Retrieved from https://www.australiancurriculum.edu.au/f-10-curriculum/general-capabilities/criticaland-creative-thinking/

Australian Government. (2013, March). Creative Australia: National cultural policy. Retrieved from http://nck.pl/media/attachments/302586/creativeaustraliapdf2.pdf

Australian Universities Teaching Committee. (2003). Teaching and learning in multimedia: Learning design. Retrieved from http://www.learningdesigns.uow.edu.au/exemplars/index.html

Ball, P. (Ed.). (2010). Assessing creativity in design: Emerging themes for engineering - An engineering subject centre guide. Loughborough: The Higher Education Subject Centre. Retrieved from https://www.heacademy.ac.uk/system/files/assessing-creativity-in-design_1.pdf 
Barab, S., \& Squire, K. (2004). Design-based research: Putting a stake in the ground. The Journal of the Learning Sciences, 13(1), 1-14. https://doi.org/10.1207/s15327809jls1301_1

Bennett, S., Agostinho, S., Lockyer, L., Kosta, L., Jones, J., Koper, R., \& Harper, B. (2007). Learning designs: Bridging the gap between theory and practice. In R. J. Atkinson, C. McBeath, S. K. A. Soong, \& C. Cheers (Eds.), ICT: Providing choices for learners and learning. Proceedings of the 2007 ASCILITE Conference (pp. 51-60). Singapore: Nanyang Technological University. Retrieved from http://www.ascilite.org/conferences/singapore07/procs/bennett.pdf

Bower, M. (2017). Design thinking and learning design. In Design of technology-enhanced learning: Integrating research and practice (pp. 121-158). Bingley: Emerald Publishing.

Bradley, D., Noonan, P., Nugent, H., \& Scales, B. (2008). Review of Australian higher education: Final report. Canberra: Commonwealth of Australia. Retrieved from https://www.mq.edu.au/_data/assets/pdf_file/0013/135310/bradley_review_of_australian_higher_educa tion.pdf

Bridgstock, R. S. (2009). The graduate attributes we've overlooked: Enhancing graduate employability through career management skills. Higher Education Research and Development, 28(1), 31-44. https://doi.org/10.1080/07294360802444347

Charmaz, K. (2011). Constructing grounded theory. Los Angeles, CA: Sage.

Conole, G., Brashera, A., Crossa, S., Wellera, M., Clarka, P., \& Culvera, J. (2008). Visualising learning design to foster and support good practice and creativity. Educational Media International, 45(3), 177194. https://doi.org/10.1080/09523980802284168

Conole, G., \& Fill, K. (2005). A learning design toolkit to create pedagogically effective learning activities. Journal of Interactive Media in Education, 8. Retrieved from https://wwwjime.open.ac.uk/articles/10.5334/2005-8/

Csikszentmihalyi, M. (2007). Creativity: Flow and the psychology of discovery and invention. New York, NY: Harper Perennial.

Dalziel, J., Wills, S., Conole, G., Walker, S., Bennett, S., Dobozy, E., ... Pegler, C. (2016). Learning design: Where do we go from here? In J. Dalziel (Ed.), Learning design: Conceptualizing a framework for teaching and learning online (pp. 256-261). New York, NY: Routledge. https://doi.org/10.4324/9781315693101

Dewey, J. (1910). How we think. Boston, MA: Heath \& Co.

Dobozy, E., \& Campbell, C. (2016). The complementary nature of learning design and TPACK. In J. Dalziel (Ed.), Learning design: Conceptualizing a framework for teaching and learning online (pp. 96-116). New York, NY: Routledge. https://doi.org/10.4324/9781315693101

EnRoLE. (2017). Roleplay search. EnRoLE: Encouraging role based online learning environments. Retrieved October 5, 2017, from http://enrole.uow.edu.au/rp repository.html

European University Association. (2007). Creativity in education: Report on the EUA creativity project 20062007. Brussels: Author. Retrieved from http://www.eua.be/activities-services/projects/pastprojects/quality-assurance-and-transaparency/creativity.aspx

Freire, P. (2000). Pedagogy of the oppressed (M. B. Ramos, Trans.). New York, NY: Continuum.

Fryer, M. (2006). Facilitating creativity in higher education: A brief account of National Teaching Fellows' views. In N. Jackson, M. Oliver, M. Shaw, \& J. Wisdom (Eds.), Developing creativity in higher education (pp. 74-88). London: Routledge.

Fryer, M. (2012). Some key issues in creativity research and evaluation as seen from a psychological perspective. Creativity Research Journal, 24(1), 21-28. https://doi.org/10.1080/10400419.2012.649236

Garzotto, F., \& Retalis, S. (2009). A critical perspective on design patterns for e- learning. In L. Lockyer, S. Bennett, S. Agostinho, \& B. Harper (Eds.), Handbook of research on learning design and learning objects: Issues, applications, and technologies (pp. 113-143). Hershey, PA: IGI Global.

Glaser, B. G., \& Strauss, A. (1967). The discovery of grounded theory. Hawthorne, NY: Aldine de Gruyter.

Gonski, D., Boston, K., Greiner, K., Lawrence, C., Scales, B., \& Tannock, P. (2011). Review of funding for schooling: Final report. Canberra: Australian Government. Retrieved from https://docs.education.gov.au/system/files/doc/other/review-of-funding-for-schooling-final-report-dec2011.pdf 
Goodyear, P. (2005). Educational design and networked learning: Patterns, pattern languages and design practice. Australian Journal of Educational Technology, 21(1), 82-101. https://doi.org/10.14742/ajet.1344

Goodyear, P., \& Dimitriadis, Y. (2013). In medias res: Reframing design for learning. Research in Learning Technology, 21, 1-13. https://doi.org/10.3402/rlt.v21i0.19909

Goodyear, P., \& Retalis, S. (2010). Learning, technology and design. In P. Goodyear \& S. Retalis (Eds.), Technology-enhanced learning: Design patterns and pattern languages (pp. 1-27). Rotterdam: Sense Publishers.

Harashima, Y., Kubota, T., \& Iba, T. (2014). Creative education patterns: Designing for learning by creating. In EuroPLoP'14. Proceedings of the 19th European Conference on Pattern Languages of Programs(pp. 1-10). New York, NY: ACM. https://doi.org/10.1145/2721956.2721989

Hasso Platner Institute of Design at Stanford. (2010). An introduction to design thinking: Process guide. Retrieved from https://dschoolold.stanford.edu/sandbox/groups/designresources/wiki/36873/attachments/74b3d/ModeGuideBOOTCA MP2010L.pdf

Jackson, N. (2006). Imagining a different world. In N. Jackson, M. Oliver, M. Shaw, \& J. Wisdom (Eds.), Developing creativity in higher education: An imaginative curriculum (pp. 1-9). London: Routledge.

Jackson, N., Oliver, M., Shaw, M., \& Wisdom, J. (Eds.) (2006). Developing creativity in higher education: An imaginative curriculum. London: Routledge.

Jackson, N., \& Shaw, M. (2006). Developing subject perspectives on creativity in higher education. In N. Jackson, M. Oliver, M. Shaw, \& J. Wisdom (Eds.), Developing creativity in higher education: An imaginative curriculum (pp. 89-108). London: Routledge.

Kaufman, A. B., Kornilov, S. A., Bristol, A. S., Tan, M., \& Grigorenko, E. L. (2010). The neurobiological foundation of creative cognition. In J. C. Kaufman \& R. J. Sternberg (Eds.), The Cambridge handbook of creativity (pp. 215-232). Cambridge: Cambridge University Press.

Kearney, M. (2009). Towards a learning design for student-generated digital storytelling. In Proceedings of the Future of Learning Design Conference (pp. 28-37). Wollongong: University of Wollongong. Retrieved from http://ro.uow.edu.au/fld/09/Program/4

Kimura, N., Shimizu, H., Ogo, I., Ando, S., \& Iba, T. (2016). Design patterns for creative education programs. In M. Zylka, H. Fuehres, A. Fronzetti Colladon, \& P. Gloor (Eds.), Designing networks for innovation and improvisation. Proceedings of the 6th international COINs conference (pp. 95-103). Cham: Springer. https://doi.org/10.1007/978-3-319-42697-6

Kohls, C. (2015). Patterns for creative thinking: Idea generation. In EuroPLoP '15. Proceedings of the 20th European Conference on Pattern Languages of Programs (pp. 1-11). New York, NY: ACM. https://doi.org/10.1145/2855321.2855352

Laurillard, D. (2012). Teaching as a design science. New York, NY: Routledge.

Laurillard, D. \& McAndrew, P. (2002). Keynote. Virtual teaching tools: Bringing academics closer to the design of e-learning. In Proceedings of the 2002 Networked Learning Conference. Lancaster \& Sheffield: Lancaster University \& University of Sheffield. Retrieved from http://www.networkedlearningconference.org.uk/past/nlc2002/proceedings/index.htm

LondonScreenwriters. (2014, September 20). John Cleese on creativity [Audio podcast]. Retrieved from https://soundcloud.com/londonscreenwriters/john-cleese-on-creativity

McWilliam, E., \& Dawson, S. (2008). Teaching for creativity: Towards sustainable and replicable pedagogical practice. Higher Education, 56(6), 663-643. https://doi.org/10.1007/s10734-008-9115-7

McWilliam, E., Dawson, S., \& Tan, J. P.-L. (2011). Less elusive, more explicit: The challenge of "seeing" creativity in action. In P. Thomson \& J. Sefton-Jones (Eds.), Researching creative learning: Methods and issues (pp. 246-273). Abingdon: Routledge.

Nagai, M., Isaku, T., Akado, Y., \& Iba, T. (2016). Generator patterns: A pattern language for collaborative inquiry. In EuroPLoP 2016. Proceedings of the 21st European Conference on Pattern Languages of Programs (pp. 1-36). New York, NY: ACM. https://doi.org/10.1145/3011784.3011817

Niu, W. (2006). Development of creativity research in Chinese societies: A comparison of mainland China, Taiwan, Hong Kong and Singapore. In J. C. Kaufman \& R. J. Sternberg (Eds.), The international handbook of creativity (pp. 374-394). Cambridge: Cambridge University Press. 
Nygaard, C., Courtney, N., \& Holtham, C. (Eds.). (2010). Teaching creativity: Creativity in teaching. Faringdon: Libri.

Oliver, B. (2011). Good practice report: Assuring graduate outcomes. Strawberry Hills: Australian Learning and Teaching Council. Retrieved from http://www.olt.gov.au/resource-assuring-graduate-outcomescurtin-2011

Philip, R. (2015a). Caught in the headlights: Designing for creative learning and teaching in higher education (Doctoral dissertation). Retrieved from https://eprints.qut.edu.au/82748/

Philip, R. (2015b). The paradox of creative uncertainty in learning and teaching. In T. Levin, P. Dawson, K. Fraser, \& R. Hadgraft (Eds.), Learning for Life and Work in a Complex World. Proceedings of the 38th HERDSA Annual International Conference (pp. 382-391). Hammondville: HERDSA. Retrieved from http://www.herdsa.org.au/publications/conference-proceedings/research-and-development-highereducation-learning-life-and-33

Philip, R., \& Cameron, L. (2008). Sharing and reusing learning designs: Contextualising enablers and barriers. In J. Luca \& E. Weippl (Eds.), Proceedings of EdMedia: World Conference on Educational Multimedia, Hypermedia and Telecommunications (pp. 453-462). Waynesville, NC: AACE. Retrieved from https://www.learntechlib.org/p/28434/

Phillips, D. C. (1995). The good, the bad, and the ugly: The many faces of constructivism. Educational Researcher, 24(7), 5-12. Retrieved from http://www.jstor.org/stable/1177059

Runco, M. A. (2011). Divergent thinking. In M. A. Runco \& S. R. Pritzker (Eds.), Encyclopedia of creativity (2nd ed.) Vol. 1, pp. 400-403). Amsterdam: Elsevier.

Runco, M. A., \& Albert, R. S. (2010). Creativity research: A historical view. In J. C. Kaufman \& R. J. Sternberg (Eds.), The Cambridge handbook of creativity (pp. 3-19). New York, NY: Cambridge University Press. https://doi.org/10.1017/CBO9780511763205

Seelig, T. (2012). Ingenius: A crash course on creativity. London: Hay House.

Smith-Bingham, R. (2006). Public policy, innovation and the need for creativity. In N. Jackson, M. Oliver, \& J. Wisdom (Eds.), Developing creativity in higher education: An imaginative curriculum (pp.10-18). London: Routledge.

Sternberg, R. J., Kaufman, J. C., \& Pretz, J. E. (2002). The creativity conundrum: A propulsion model of kinds of creative contributions. New York, NY: Psychology Press.

Strauss, A., \& Corbin, J. (1990). Basics of qualitative research: Grounded theory procedures and techniques. Newbury Park, CA: Sage.

Swirski, T. (2012). Becoming a creative practitioner in a complex society: Fostering a capability approach in higher education pedagogy (Unpublished doctoral dissertation). Macquarie University, Sydney, Australia.

Thornberg, R. (2012). Informed grounded theory. Scandinavian Journal of Educational Research, 56(3), 243-259. https://doi.org/10.1080/00313831.2011.581686

Walker, C., \& Gleaves, A. (2008). An exploration of students' perceptions and understandings of creativity as an assessment criterion in undergraduate-level studies within higher education. Irish Educational Studies, 27(1), 41-54. https://doi.org/10.1080/03323310701837855

Wills, S., Leigh, E., \& Ip, A. (2011). The power of role-based e-learning. New York, NY: Routledge.

Corresponding author: Robyn Philip, rl.philip@qut.edu.au

Australasian Journal of Educational Technology @ 2018.

Please cite as: Philip, R. (2018). Finding creative processes in learning design patterns. Australasian Journal of Educational Technology, 34(2), 78-94. https://doi.org/10.14742/ajet.3787 